Liau, et al.

\title{
Mixing Crowded Biological Solutions in Milliseconds
}

Albert Liau $^{1^{*}}$, Rohit Karnik ${ }^{2^{*}}$, Arun Majumdar $^{2,3}$, Jamie H. Doudna Cate ${ }^{4,5 \dagger}$

${ }^{1}$ Biophysics Program, University of California, Berkeley, CA 94720.

${ }^{2}$ Department of Mechanical Engineering, University of California, Berkeley, CA 94720.

${ }^{3}$ Materials Sciences Division, Lawrence Berkeley National Laboratory, Berkeley, CA 94720.

${ }^{4}$ Departments of Molecular and Cell Biology and Chemistry, University of California, Berkeley, CA 94720.

${ }^{5}$ Physical Biosciences Division, Lawrence Berkeley National Laboratory, Berkeley, CA 94720.

*These authors contributed equally to this paper.

${ }^{\dagger}$ Corresponding author: Department of Chemistry, University of California at Berkeley, Berkeley, CA 94720, USA. Phone- (510) 486 4033, Fax- (510) 486 6240, Email- jcate@lbl.gov

\begin{abstract}
In vitro studies of biological reactions are rarely performed in conditions that reflect their native intracellular environments where macromolecular crowding can drastically change reaction rates. Kinetics experiments require reactants to be mixed on a timescale faster than that of the reaction. Unfortunately, highly concentrated solutions of crowding agents such as bovine serum albumin and hemoglobin that are viscous and sticky are extremely difficult to mix rapidly. We demonstrate a new droplet-based microfluidic mixer that induces chaotic mixing of crowded solutions in milliseconds due to protrusions of the microchannel walls that generate oscillating interfacial shear within the droplets. Mixing in the microfluidic mixer is characterized, mechanisms underlying mixing are discussed and evidence of biocompatibility is presented. This microfluidic platform will allow for the first kinetic studies of biological reactions with millisecond time resolution under conditions of macromolecular crowding similar to those within cells.
\end{abstract}


Liau, et al.

\section{Supplementary Information}

Sticking and Swirling. The most detrimental problem encountered with crowded solutions in the original micromixer was the sticking of the crowded solutions to the microchannel walls (Figure S-1a). Within seconds to minutes of starting the flows in the micromixer, this phenomenon began and was irreversible. Stopping the streams of crowded solutions and flushing the micromixer with the oil carrier fluid did not succeed in effectively removing the stuck solution. In addition, the leading edge of stuck protein, which we refer to as the "sticking front", advanced further down the channel over time (Figure S-1b). The inclusion of the perfluorinated coating fluid EGC-1702 in the oil carrier stream effectively prevented sticking, facilitating robust plug formation with $\mathrm{Hb}$ and BSA solutions for over an hour (Figure 2).

Swirling at the point of plug formation partially mixed the fluids before the plug fully formed (pre-mixing), thus making the time required for mixing difficult to quantify. Swirling wrapped the first crowded solution to come into contact with the oil around the forming plug (Figure S-1c) and, if it continued long enough, folded the crowded solution into the plug as it formed. The extent to which swirling pre-mixed fluid in forming plugs was sensitive to the relative flow rates of the oil and crowded streams but was present over a wide range of total flow rates in our experiments. By using two oil streams positioned symmetrically at the point of plug formation, swirling was effectively minimized (Figure S-1d). Inclusion of two oil streams also decreased the tendency to form a sticking front. 
Liau, et al.

Calculation of Flow Speed and Ca. Using long exposure photographs, we observed that a plug required $5 \mathrm{~ms}$ to traverse one cycle of the bumpy serpentine mixer at a total flow rate of $1 \mu \mathrm{L} / \mathrm{min}$. The number of cycles traversed by the plugs per second $(N)$ is therefore calculated as follows:

$$
N=[200 \times(\text { flow rate in } \mu \mathrm{L} / \mathrm{min})] \text { cycles/second }
$$

The inner and outer radii of the bumpy serpentine channels are $40 \mu \mathrm{m}$ and $60 \mu \mathrm{m}$, respectively, with a total arc angle of $250^{\circ}$ per half cycle. From this, the average arc length per cycle $\left(S_{c y c l e}\right)$ is $4.36 \times 10^{-4} \mathrm{~m}$ and the flow speed of the plugs $(V)$ can be calculated as follows:

$$
V=S_{c y c l e} \times N=[0.0872 \times(\text { flow rate in } \mu \mathrm{L} / \mathrm{min})] \mathrm{m} / \mathrm{s}
$$

With the assumption that surface tension and viscosity of the oil carrier fluid are approximately $5 \mathrm{mN} / \mathrm{m}$ and $5 \mathrm{mPa} \cdot \mathrm{s}$ respectively, the capillary number can be calculated as follows:

$$
\left.\mathrm{Ca}=\mu_{0} \mathrm{~V} / \gamma=0.0872 \times \text { (flow rate in } \mu \mathrm{L} / \mathrm{min}\right)
$$

For the range of flow rates reported in the present work, $\mathrm{Ca}$ therefore ranges between 0.04 and 1.4. However, the dynamic changes in plug shape discussed below indicate that this Ca may not be fully descriptive of the system behavior.

Behavior of $100 \mathrm{mg} / \mathrm{mL}$ BSA. Plugs containing $100 \mathrm{mg} / \mathrm{mL}$ BSA and Calcein dye showed very little circulation in the original micromixer (Figure S-2a). This further suggests that viscosity is not the dominant factor that impedes fluid circulation in the plugs. In the bumpy serpentine mixer, plugs of $100 \mathrm{mg} / \mathrm{mL}$ BSA mixed rapidly. However, the evolution of dye distribution differed from that seen for $200 \mathrm{mg} / \mathrm{mL} \mathrm{BSA}$ 
Liau, et al.

and the $1: 2$ mixture of $260 \mathrm{mg} / \mathrm{mL} \mathrm{BSA}$ and $300 \mathrm{mg} / \mathrm{mL} \mathrm{Hb}$, as individual striations were less distinct (Figure S-2b). The flow still appeared to be largely two-dimensional when compared with the aqueous case (Figure 2a).

Dynamic Nature of Plug Shape. The most dramatic difference observed between plugs of $100 \mathrm{mg} / \mathrm{mL}$ and $200 \mathrm{mg} / \mathrm{mL} \mathrm{BSA}$ is the degree to which the shape of the plug changed after long distances in the channels (Figure S-2b). As the plug traversed the bumpy serpentine channel, the posterior end of the plug developed concavity that became pronounced further down the bumpy serpentine channel. This phenomenon is discussed in the review by Olbricht ${ }^{1}$. Although this change was observed in the case of $200 \mathrm{mg} / \mathrm{mL}$ BSA plugs and plugs of $260 \mathrm{mg} / \mathrm{mL} \mathrm{BSA}$ and $300 \mathrm{mg} / \mathrm{mL} \mathrm{Hb}$, it was not large even after 10-15 cycles of the bumpy serpentine channel. This suggests that the mixer induces a dynamic plug-oil interface. We therefore believe that characterizing these systems in terms of capillary numbers is incomplete. Adsorption of proteins at interfaces involves processes at two length scales ${ }^{2}$, a diffusion-limited adsorption, on a timescale much smaller than that of the evolution of the plug shape, and a rearrangement process on a much longer timescale. One possible explanation for the observed changes is that extension of the interface at each bump allows more protein to adsorb on the interface, thus decreasing the surface tension. The behavior of the interface remains unclear and will require further investigation. 
Liau, et al.

\section{References}

${ }^{1}$ Olbricht, W. L. Annu. Rev. Fluid. Mech. 1996, 28, 187-213.

${ }^{2}$ Graham, D. E.; Phillips, M. C. J. Colloid Int. Sci. 1979, 70, 403-414. 
Liau, et al.

Table S-1. Viscosities of fluids used in the bumpy serpentine micromixer.

Fluid $\quad$ Viscosity (mPa.s)

Fluorinert $\quad 24.6 \pm 1.1$

Oil Carrier Fluid $\quad 4.9 \pm 0.1$

$200 \mathrm{mg} / \mathrm{mL}$ BSA $\quad 3.9 \pm 0.2$

$300 \mathrm{mg} / \mathrm{mL} \mathrm{Hb} \quad 6.8 \pm 0.2$

$1.8 \mathrm{M}$ sucrose $\quad 29.5 \pm 0.9$ 
Liau, et al.

Table S-2. Interfacial tensions of plug fluids with the oil carrier fluid.

Drop fluid $\quad \underline{\text { Interfacial tension }(\mathrm{mN} / \mathrm{m})}$

Water

$200 \mathrm{mg} / \mathrm{mL}$ BSA

$270 \mathrm{mg} / \mathrm{mL} \mathrm{Hb}$

$1: 2$ mixture of

$260 \mathrm{mg} / \mathrm{mL}$ BSA:

$300 \mathrm{mg} / \mathrm{mL} \mathrm{Hb}$
$17.4 \pm 0.1$

$6.0 \pm 0.7$

$4.7 \pm 0.1$

$4.5 \pm 0.8$ 
Liau, et al.

Figure S-1. Sticking and swirling of crowded solutions in the original mixer but not in the bumpy serpentine mixer. Crowded solutions can stick across the entire width of the channel (a) or cling to one side of the channel wall (b), in which case plugs form at the sticking front (white arrow). (c) Swirling-induced wrapping of the fluid that first comes into contact with oil stream around the forming plug. (d) Elimination of swirling for plugs of $200 \mathrm{mg} / \mathrm{ml} \mathrm{BSA} \mathrm{(left),} \mathrm{and} \mathrm{unambiguous} \mathrm{distribution} \mathrm{of} \mathrm{dye} \mathrm{within} \mathrm{plugs} \mathrm{(right)} \mathrm{due} \mathrm{to}$ the symmetrical oil streams.

Figure S-2. The behavior of $100 \mathrm{mg} / \mathrm{ml} \mathrm{BSA}$ in the original and bumpy serpentine mixers. (a) Plugs of $100 \mathrm{mg} / \mathrm{ml} \mathrm{BSA}$ show some circulation in the original mixer, but it is insufficient to achieve rapid mixing. Oil streams and BSA streams were driven at flow rates of $2 \mu \mathrm{l} / \mathrm{min}$ and $0.2 \mu \mathrm{l} / \mathrm{min}$, respectively. (b) In the bumpy serpentine mixer, plugs of $100 \mathrm{mg} / \mathrm{ml} \mathrm{BSA} \mathrm{mix} \mathrm{rapidly} \mathrm{with} \mathrm{circulation} \mathrm{patterns} \mathrm{markedly} \mathrm{different} \mathrm{from} \mathrm{those}$ seen in $200 \mathrm{mg} / \mathrm{ml} \mathrm{BSA}$ and plugs composed of $300 \mathrm{mg} / \mathrm{ml} \mathrm{Hb}$ and $260 \mathrm{mg} / \mathrm{ml} \mathrm{BSA}$. The shape of the $100 \mathrm{mg} / \mathrm{ml} \mathrm{BSA} \mathrm{plugs} \mathrm{also} \mathrm{changes} \mathrm{dramatically} \mathrm{further} \mathrm{down} \mathrm{the}$ channel. Oil streams and BSA streams were driven at flow rates of $2 \mu \mathrm{l} / \mathrm{min}$ and 0.8 $\mu \mathrm{l} / \mathrm{min}$, respectively. 
Liau, et al.

Figure S-1, Liau et al.
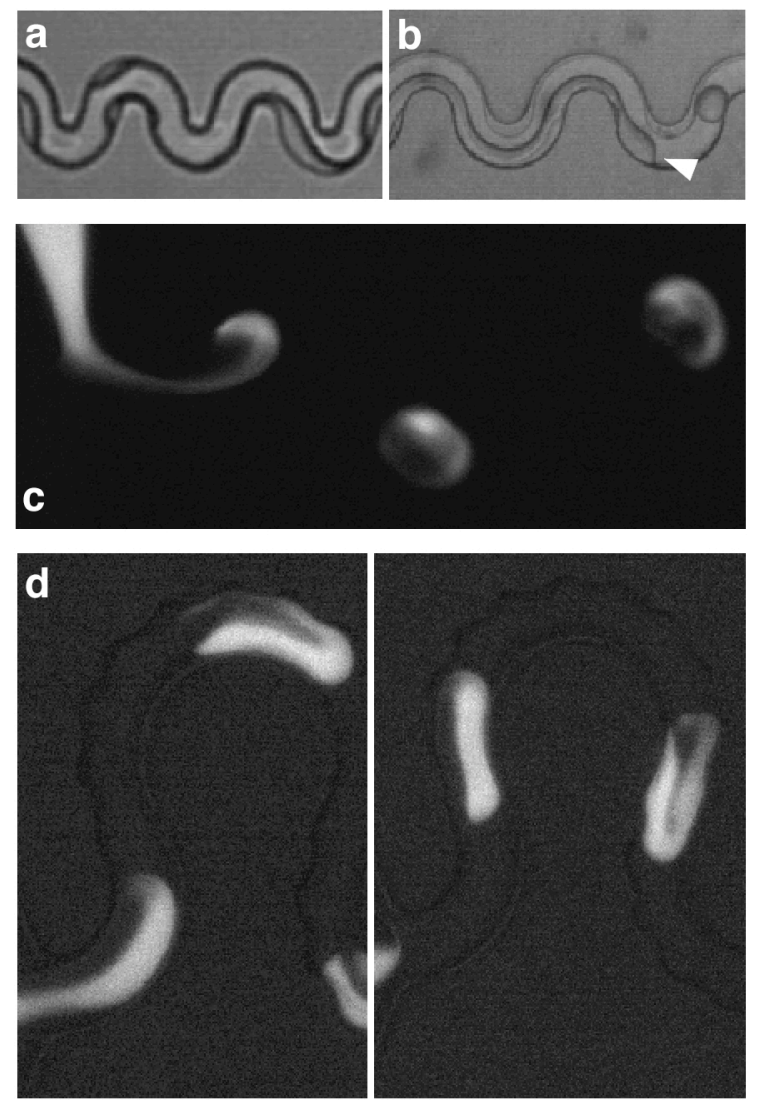
Liau, et al.

Figure S-2, Liau et al.

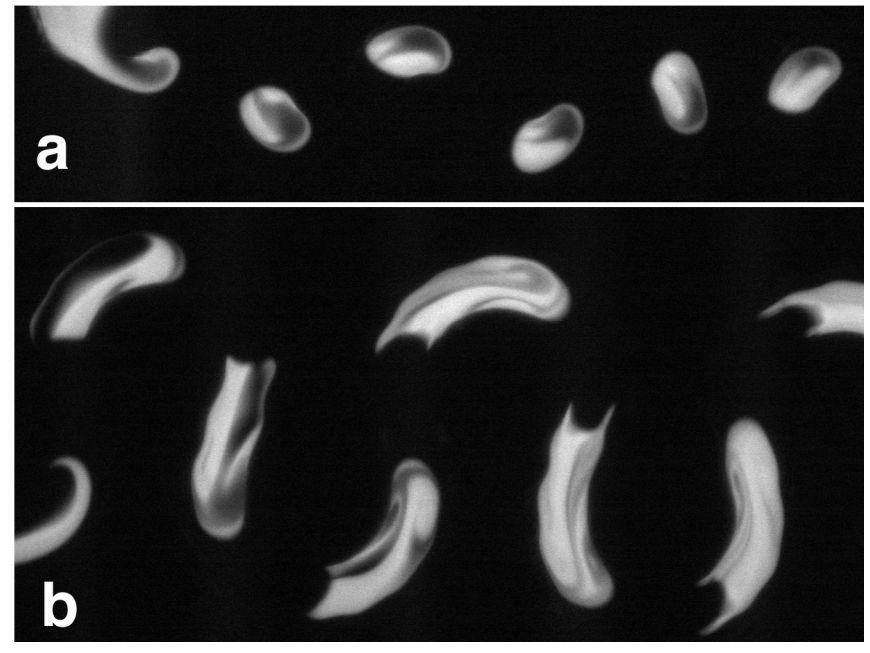

